\title{
REVISIÓN
}

\section{Toxicidad del cianuro. Investigación bibliográfica de sus efectos en animales $y$ en el hombre}

\author{
Cyanide toxicity. Bibliography research of its effects in animals and man
}

\author{
Augusto V. Ramírez ${ }^{1,2}$ \\ ${ }^{1}$ Dirección Salud Ocupacional. Clínica Los Fresnos. Cajamarca, Perú. \\ ${ }^{2}$ American College of Occupational and Environmental Medicine.
}

La prevención, el mejor antídoto

\begin{abstract}
Resumen
Se llama cianuro al cianuro en sí, al cianuro de hidrógeno y a sus sales. Los cianuros existen en forma natural e industrialmente se les obtiene como sales. Aún a dosis bajas son compuestos letales en tiempo mínimo de exposición. El sistema nervioso es su órgano blanco primario. Luego de ingestión, inhalación o contacto se presentan efectos neurotóxicos graves y mortales en humanos y animales. La exposición ocupacional produce alteraciones tiroideas, cefalea, vértigo, vómito, náuseas, dermatitis y exposiciones altas; a corto tiempo, terminan en paro respiratorio y muerte. Algunos compuestos de cianuro en microcantidades son indispensables para la vida. Respecto a su poder carcinógeno, al cianuro se le considera en el grupo D de los 'no clasificables como carcinógenos humanos'. Para aplicar mejor las medidas preventivas en el trabajo con cianuros, y en salud pública, es necesario conocer satisfactoriamente su acción tóxica sobre los animales y el hombre.

Palabras clave: Cianuros; exposición ocupacional; acciones tóxicas; neurotóxicos.
\end{abstract}

\begin{abstract}
Cyanide, hydrogen cyanide and its salts are called cyanide. They exist in natural form and are obtained as salts in industry. At low doses they are lethal in minimum exposure time. The nervous system is its primary target organ. After ingestion, contact or inhalation, serious neurotoxic effects appear in humans and animals. Occupational exposure can produce headache, vertigo, vomiting, nausea, thyroid gland alterations, and dermatitis. At high doses and in short time, cyanide exposure can end in death. In very low amounts some cyanide compounds are indispensable for life. Cyanide is located in group D "not classifiable as human carcinogen". In order to apply preventive measures when working with cyanides and in public health, it is necessary to acknowledge cyanide toxic effects on men and animals.
\end{abstract}

Key words: Cyanides; Toxicology in animals and humans; occupational exposure; toxic actions; neurotoxins.

\section{INTRODUCCIÓN}

El cianuro, químico altamente reactivo y muy tóxico, es utilizado desde hace mucho por su acción rápida y letal con fines homicidas o suicidas. Hoy recupera actualidad debido al éxito de la lixiviación química en metalurgia de metales pesados y al desarrollo de la química aplicada que ha creado compuestos muy útiles en la vida diaria, pero que al ser quemados se tornan mortales. Además, porque las últimas grandes catástrofes ambientales lo han tenido como protagonista; allí están Bophal, en la India, y Baia Mare, en Rumania y, por si fuera poco, la amenaza de su uso por el terrorismo sigue siendo una espada de Damocles sobre la humanidad. Si, como es sabido, no hay venenos y todo depende de la dosis, lo que convoca a este escrito es conocer mejor al tóxico para propiciar su manejo seguro en salud pública y ocupacional.
El cianuro tiene múltiples usos: en metalurgia para obtener oro por lixiviación química; en la industria del acero; en joyería; en laboratorios químicos y clínicos; en la industria de pegamentos y plásticos; en pinturas; como solvente y esmalte; como herbicida, plaguicida y fertilizante. Además, al quemar lana, seda, poliuretano o vinilo se liberan acronitrilos, compuestos que contienen al grupo funcional cianuro.

El cianuro de hidrógeno es líquido, incoloro, de olor característico a almendras amargas, peso molecular de 27,03, punto de ebullición de $25,6^{\circ} \mathrm{C}$, no combustible, miscible en agua y alcohol y soluble ligeramente en éter. Sus sales son oxidantes fuertes, incompatibles con nitratos, cloratos y ácidos.

La nomenclatura industrial específica para cianuro es CAS No. 57-12-5 y para cianógenos en general CAS 460 . $19-5$.
Individualmente para otros compuestos la nomenclatura industrial es:

Cianuro de hidrógeno, CAS No. 7490-8; cianuro de sodio, CAS No. 143-33-9; cianuro de potasio, CAS No. 151-50-8 y para los acetonitrilos CAS 75-05-8.

Coloquialmente, se llama cianuro al cianuro de hidrógeno o ácido cianhídrico $(\mathrm{HCN})$ y a sus sales, cianuro de sodio o de potasio, y no solo al compuesto raíz cianuro, $-\mathrm{C} \equiv \mathrm{N}$, que da origen a la denominación. Se le encuentra en forma natural como componente orgánico en algunas plantas o semillas de frutas -glucósidos cianogénicos- y también es producido por ciertas bacterias, hongos y algas. Por lo demás, en microcantidades el cianuro es un compuesto indispensable en la dieta humana.

Su acción biológica lo caracteriza como un inhibidor enzimático no específico; inhibe varias enzimas, tales la succinildeshidrogenasa, la superóxido- 
dismutasa, la anhidrasa carbónica, la citocromooxidasa y otras, bloqueando la producción de ATP e induciendo hipoxia celular.

El sistema nervioso central (SNC) es su órgano blanco primario, pero también la tiroides y el riñón. En animales, se ha demostrado que puede producir fetotoxicidad y efectos teratógenos, como encefalocele, exencefalia y anormalidades en el desarrollo de los arcos costales.

El cuadro clínico describe deterioro mental, trastornos visuales por atrofia del nervio óptico, alteraciones tiroideas, dermatitis de características variables, aunque siempre con el fondo de una piel color rojo cereza, debido al incremento de la saturación de la hemoglobina en sangre venosa. En determinados casos se puede hallar cianosis.

La exposición a cianuro ocurre en variedad de ocupaciones, que van de la metalurgia a la industria de plásticos y a los bomberos. La población general se puede exponer al cianuro por inhalación de aire ambiental contaminado, ingestión de agua contaminada o alimentos -como la yuca, raíz liliácea alimenticia que contiene glucósidos cianogénicos que cuando se metabolizan in vivo liberan el núcleo funcional $-\mathrm{C} \equiv \mathrm{N}$.

No se dispone de bioensayos o estudios epidemiológicos suficientes para determinar los efectos carcinógenos del cianuro, por lo que aún se le considera en el 'grupo D' de los 'no clasificables como carcinógenos humanos' (1-7).

\section{CUADRO CLÍNICO}

En el cuadro clínico de exposición a cianuros no hay nada patognomónico, pero el antecedente de exposición, la aparición temprana y progresiva de síntomas y signos de hipoxia -cefalea, agitación, confusión, convulsiones, tendencia al sueño o coma- deciden el diagnóstico. Solo en $40 \%$ de los casos de liberación de cianuro se puede percibir el descrito olor a almendras amargas.

Cuando es ingerido, se presentan trastornos gastrointestinales, dolor abdominal, náuseas y vómitos. Si el ingreso es por inhalación, los síntomas se presentan muy rápidamente -al cabo de pocos minutos- taquipnea, pero luego bradipnea y bradicardia con hipotensión. El cianuro de hidrógeno y los compuestos cianúricos son venenos muy activos sobre el sistema nervioso central, el más sensible del organismo a la falta de oxígeno. Clínicamente, la ingestión entre 50 y $100 \mathrm{mg}$ de cianuro de sodio o potasio es seguida de inconciencia y paro respiratorio. A dosis más bajas, los síntomas tempranos son debilidad, cefalea, confusión. Cuando aparece cianosis es signo de que la respiración ha cesado en los minutos previos. En caso de intoxicación por compuestos cianogénicos, los síntomas pueden tardar horas en aparecer.

Si después de una exposición moderada el paciente se recupera, puede presentar secuelas en el SNC, como trastornos de la personalidad, síndrome extrapiramidal y déficit de memoria ${ }^{(4)}$.

\section{TOXICOCINÉTICA}

\section{Absorción}

$\mathrm{Al}$ inhalar sus vapores, el cianuro se absorbe instantáneamente. Si se ingiere en forma líquida es absorbido por los tractos gastrointestinal y respiratorio. Se puede absorber también directamente por la piel intacta ${ }^{(1,2)}$. El cianuro de hidrógeno se absorbe más pronto desde el tracto gastrointestinal que sus sales. Gettler y Baine, en 1938, informaron sobre perros que recibieron por sonda gástrica 20, 50, y $100 \mathrm{mg} / \mathrm{kg}$ de cianuro de potasio y absorbieron 17,24, y $72 \%$, respectivamente, de la dosis administrada ${ }^{(8)}$. Landahl y Hermann, en 1 950, informaron que el humano retiene en pulmones entre $57 \mathrm{y}$ $77 \%$ del $\mathrm{HCN}$ inhalado ${ }^{(9)}$. La absorción de gas cianuro desde el humo de tabaco es causante del alto nivel de tiocianato en el plasma de fumadores ${ }^{(10,11)}$. Los cianuros son ligeramente liposolubles; por ello, penetran la epidermis y sus sales tienen efecto corrosivo en la piel, factor que incrementa su absorción dérmica ${ }^{(1,2)}$.

\section{Distribución}

Luego de absorbidos, los cianuros son distribuidos a todo el organismo por la sangre y, aunque en ella su concentración es baja, logran penetrar al eritrocito y en gestantes atraviesan la barrera placentaria, lo que determina su alto contenido en el cordón umbilical de neonatos de fumadoras comparados con neonatos de no fumadoras ${ }^{(8,12)}$. Después de una exposición no letal, su vida media total se estima entre 4 y 8 horas, pero su vida media en plasma solo sería entre $20 \mathrm{mi}$ nutos y 1 hora ${ }^{(1,2,13)}$.

En humanos que ingieren dosis letales de cianuro se informa niveles en cerebro entre 0,06 y $1,37 \mathrm{mg} / 100 \mathrm{~g}$, y de 0,22 a 0,91 $\mathrm{mg} / 100 \mathrm{~g}$ en mucosa gástrica ${ }^{(8)}$. Se encuentra que los niveles en tejidos humanos después de inhalación de $\mathrm{HCN}$ son: 0,75, $0,42,0,41,0,33,0,30$ y $0,32 \mathrm{mg} / 100 \mathrm{~g}$ de pulmón, corazón, sangre, riñón, páncreas, cerebro, respectivamente ${ }^{(14,15)}$. En ratas a las que se les administra comida fumigada con ácido cianhídrico se halla nivel alto de cianuro en hematíes y de tiocianato en sangre, hígado, y riñón ${ }^{(16)}$.

\section{Metabolismo}

La vía natural de metabolismo del cianuro es su conversión a tiocianato, catalizada por las enzimas rodanasa, tiosulfatosulfuro-transferasa y/o la 3-mercaptopiruvatosulfuro-transferasa, a las que se les encuentra ampliamente distribuidas en el organismo. La conversión de cianuro a tiocianato por la rodanasa se refuerza cuando la intoxicación es tratada con administración EV de tiosulfato de sodio, un dador de azufre ${ }^{(1,2,17,18)}$. La toxicidad del tiocianato es significativamente menor que la del cianuro, aun cuando su elevación crónica pueda inhibir la captación de yodo por la tiroides y reducir la formación de tiroxina. Otras vías metabólicas del cianuro incluyen 1) la incorporación de un carbono del pool metabólico y su posterior conversión a 2-aminotioazolina-4-ácidocarboxílico; 2) su combinación con hidroxicobalamina para formar cianocobalamina (B12); y, por último, 3) su combinación con cistina y formación de 4-ácido carboxílico-2aminotiazolina ${ }^{(1-2)}$.

\section{Excreción}

En humanos y animales, la ruta de mayor eliminación de cianuro como tiocianato es la vía urinaria, pero en 
pequeñas cantidades también se elimina por las vías respiratoria y digestiva. Una porción de cianuro libre se excreta inalterado con la respiración, saliva, sudor, y orina ${ }^{(1,2)}$. Ratas que ingieren agua con $160 \mathrm{mg} / \mathrm{kg} /$ día de cianuro, durante 13 semanas, no muestran saturación de sus vías de detoxificación ${ }^{(19)}$.

Se observa aumento de excreción urinaria de tiocianato en trabajadores que manipulan endurecedores de plástico que contienen el tóxico y se exponen a concentraciones mayores a 5 ppm por varios años ${ }^{(20)}$.

\section{Toxicodinámica}

En condiciones normales, la citocromooxidasa tiene papel primordial en la utilización del oxígeno por la célula. Su inhibición conlleva interrupción de la respiración celular que deriva en hipoxia citotóxica y, precisamente, el cianuro es tóxico para el organismo debido a que se une al ión férrico de la citocromooxidasa en la mitocondria e interrumpe el uso del oxígeno por la célula, condicionando que la saturación de $\mathrm{O}_{2}$ en la sangre venosa y arterial sea igual. Así, paradójicamente, el intoxicado muere por hipoxia, pero ahogado en un mar de oxígeno al que no puede utilizar; el color rojo brillante de la sangre venosa evidencia esa incapacidad. Además, el cianuro se liga al 2\% de la metahemoglobina presente en el organismo $(1,2,21-23)$

\section{TOXICIDAD DE LOS CIANUROS: EFECTOS NO CARCINOGÉNICOS}

\section{A. Exposición oral}

\section{Toxicidad aguda.-}

\section{En animales de experimentación}

Gettler y Baine informan que tratan oralmente a perros con 20,50 y $100 \mathrm{mg} /$ $\mathrm{kg}$ cianuro de potasio y mueren a los 155 , 21 y 8 minutos después de la ingestión, respectivamente ${ }^{(8)}$. La DL50 oral en ratas es $8,5 \mathrm{mg} / \mathrm{kg}$ para el cianuro de hidrógeno, $6,4 \mathrm{mg} / \mathrm{kg}$ para cianuro de sodio, $10 \mathrm{mg} /$ $\mathrm{kg}$ para cianuro de potasio, $39 \mathrm{mg} / \mathrm{kg}$ para cianuro de calcio ${ }^{(24)}$.

\section{Toxicidad humana}

Muchas comunicaciones describen intentos de suicidio por ingestión de compuestos de cianuro, pero generalmente no señalan las dosis. Se calcula que en humanos la dosis letal promedio por ingestión es $200 \mathrm{mg}$ de $\mathrm{CNK}$ o $\mathrm{CNNa}^{(14)}$. Wolnik informa de siete muertos postingesta de un analgésico contaminado con $650 \mathrm{mg}$ de cianuro de potasio ${ }^{(25)}$. Otra investigación consigna envenenamiento por cianuro en un niño de 2 años que ingiere un 'removedor' de laca de uñas que contiene acetonitrilo. Se sabe que cuando se ingiere acetonitrilo, este se metaboliza muy lentamente; entonces, para la intervención terapéutica el médico cuenta con un tiempo prudente, lo que favorece una acción temprana ${ }^{(26)}$.

\section{Toxicidad sobre el sistema reproductor y el desarrollo fetal.-}

\section{En animales de experimentación}

No se observa efectos adversos en el proceso reproductivo ni durante la lactancia en ratas preñadas y lactantes alimentadas hasta con $500 \mathrm{mg}$ de cianuro por kg; el desarrollo, peso del producto al nacer, consumo de alimento y crecimiento no son significativamente diferentes de los controles ${ }^{(24,27)}$.

Pero, los fetos de cerdas alimentadas durante su gestación con glúcidos cianogénicos provenientes de yuca con dosis entre 277 y $521 \mathrm{mg}$ por kg presentan disminución del peso de tiroides, corazón y bazo proporcional a la disminución de su peso corporal, comparado con los nacidos de cerdas alimentadas con $31 \mathrm{mg}$ por $\mathrm{kg}$; pero, las cerdas-madre de ambos grupos presentan hiperplasia glomerular y cambio morfológico en las células tiroideas $(19,28)$.

Frakes experimentó con hámsteres hembras expuestas a cianógenos de yuca entre los días 3 y 14 de su gestación -la cantidad más baja de cianógeno proporcionado fue $0,6 \mathrm{mmol} / \mathrm{kg}$ (46 ppm) y la más alta $7,9 \mathrm{mmol} / \mathrm{kg}$ (600 ppm)-; como resultado, las hámsteres ganaron menos peso que los controles y su descendencia tuvo también menor peso fetal y retardo en la osificación ${ }^{(29)}$.
En otro estudio, hámsteres tratados oralmente con dosis entre 200 y 275 $\mathrm{mg} / \mathrm{kg}$ DL-amigdalina (otro glucósido cianogénico), en el día 8 de gestación, mostraron signos de toxicidad ya a dosis de $250 \mathrm{mg} / \mathrm{kg}$-exencefalia, encefalocele y anormalidades en la formación de arcos costales-; estos efectos fueron atribuidos al cianuro liberado por acción bacteriana en el tracto gastrointestinal a partir del cianógeno. El mismo estudio describe otro grupo al que junto con amigdalina administró tiosulfato y halló que este protege contra el tóxico ${ }^{(30)}$.

\section{Toxicidad humana}

En ciertas regiones de África, donde la yuca es comida principal en la dieta, se reporta problemas neurológicos, bocio, cretinismo y en general hipotiroidismo congénito hasta en 15\% de recién nacidos, incidencia 500 veces mayor a la de países sin esa dieta ${ }^{(31-36)}$.

\section{Toxicidad subcrónica.-}

\section{En animales de experimentación}

En ratas adultas expuestas a $200 \mathrm{mg}$ de cianuro de potasio por litro de agua durante 21 días se encuentra, respecto a los controles, aumento significativo de peso del hígado, pero no cuando el cianuro es administrado a la misma dosis junto con la dieta ${ }^{(24)}$. Palmer informa prevención parcial de la intoxicación cianúrica subcrónica en ratas usando selenio ${ }^{(37)}$.

No se ha observado efectos adversos en perros expuestos a cianuro de sodio ingerido con la dieta a las dosis de $3 \mathrm{mg} /$ kg de peso/día por 30 y 32 días ${ }^{(38)}$.

\section{Toxicidad humana}

No se dispone de información en toxicidad subcrónica al cianuro en el humano ${ }^{(1-3)}$.

\section{Toxicidad crónica.-}

\section{En animales de experimentación}

Howard y Hanzal encontraron que ratas de ambos sexos expuestas a dieta fumigada con diferentes niveles de cianuro de hidrógeno durante 104 semanas -un grupo con dosis de hasta 76 y otro 
entre 76 y $190 \mathrm{mg}$ de $\mathrm{HCN} / \mathrm{kg}$ - no desarrollaron efectos en relación a toxicidad, crecimiento corporal ni lesión alguna en los tejidos examinados ${ }^{(16)}$.

Philbrick trató ratas machos con dieta de cianuro de potasio hasta por $1,5 \mathrm{~g} / \mathrm{kg}$ durante 11,5 meses; al final del estudio halló retardo en el crecimiento y en la ganancia de peso; en el sistema nervioso, encontró degeneración primaria de la mielina en médula espinal. A los 4 meses de iniciado el estudio ya se presentaba disminución de los niveles plasmáticos de tiroxina, que se recuperaron al final. Los grupos mantenidos con dieta deficiente en metionina o en vitamina B12 sufrieron mayores estigmas ${ }^{(39)}$.

\section{Toxicidad humana}

En África, la incidencia alta de neuropatía atáxica, bocio, ambliopía y varios otros desórdenes neurológicos se asocia con ingesta habitual de yuca ${ }^{(31-36)}$. De otro lado, las dietas bajas en vitamina B12, riboflavina o proteínas exacerban el efecto neurotóxico del cianuro ${ }^{(23)}$.

\section{B. Exposición respiratoria}

\section{Toxicidad aguda.-}

\section{En animales de experimentación}

La inhalación de cianuro lleva rápidamente a toxicidad aguda y muerte. Higgins, en 1972, informa una DL50 respiratoria de $323 \mathrm{ppm}$ para ratones y 503 ppm para ratas expuestas a HCN durante 5 minutos ${ }^{(40)}$. La DL50 estimada para 30 minutos fue $142 \mathrm{ppm}$ en ratas, de $182 \mathrm{ppm}$ para gatos y $410 \mathrm{ppm}$ para cabras (41). Monos expuestos entre 87 y 196 ppm de $\mathrm{HCN}$ durante 30 minutos presentaron pérdida de conciencia, hiperventilación, bradicardia, arritmia, y onda $\mathrm{T}$ anormal en el electrocardiograma ${ }^{(42)}$.

\section{Toxicidad humana}

La literatura cita numerosos casos de intoxicación cianúrica aguda por vía respiratoria en humanos y también que de las diferentes vías de exposición esta es la más efectiva para todos los compuestos de cianuro. De ellos, el ácido cianhídrico es el que actúa casi de inmediato produciendo paro respiratorio y muerte en solo minutos ${ }^{(1-3)}$. Así, la inhalación de 270 ppm de $\mathrm{HCN}$ es mortal inmediatamente. Exposiciones entre 110 y 135 ppm son fatales antes de 1 hora y su DL50 estimada es 546 ppm luego de 10 minutos ${ }^{(13)}$.

\section{Exposición por otras vías de ingreso}

\section{Toxicidad aguda.-}

\section{En animales de experimentación}

Efectos neurotóxicos, que incluyen convulsiones y coma, preceden la muerte de cobayos expuestos a $\mathrm{HCN}$ por vía dérmica ${ }^{(43)}$. La DL50 para conejos a los que se instiló solución de cianuro de hidrógeno en la bolsa conjuntival del ojo fue $1,09 \mathrm{mg} / \mathrm{kg}, 7,87 \mathrm{mg} / \mathrm{kg}$ para cianuro de potasio y $5,05 \mathrm{mg} / \mathrm{kg}$ para cianuro de sodio. Para todos ellos, los signos de toxicidad y muerte ocurrieron entre 3 y 12 minutos postinstilación ${ }^{(44)}$.

\section{Toxicidad humana}

Rieders, en 1971, informó de muertes humanas ocurridas por exposición dérmica a solución al 5\% de cianuro de hidrógeno y a soluciones al 10\% de cianuro de potasio ${ }^{(41)}$.

\section{Toxicidad subcrónica.-}

\section{En animales de experimentación}

Al estudiar los efectos del HCN sobre la ultraestructura de células miocárdicas, no se ha encontrado efectos significativos en la exposición continua de conejos a $0,55 \mathrm{mg} / \mathrm{m}^{3}$ durante 28 días; tampoco existieron problemas miocárdicos en otros animales ${ }^{(22,45)}$.

\section{Toxicidad humana}

Trabajadores expuestos por su labor en forma intermitente a vapores de HCN presentan nerviosismo, pérdida de apetito, cefalea, vértigo, náuseas y vómito. Sandberg, en 1967, describió síntomas de toxicidad por cianuro en un joyero que pulía oro 5 a 10 veces por día, exponiéndose a una solución pulidora de cianuro de potasio y peróxido de hidrógeno; para preparar esta solución, la hervía, lo que liberaba vapor de $\mathrm{HCN}$; por ello tuvo doble exposición: contacto con piel al pulir e inhalación de vapores de cianuro. Los síntomas descritos por Sandberg incluían cefalea, apatía, entumecimiento muscular, paresia de brazo y pierna izquierdos, pérdida parcial de visión en el ojo izquierdo y alteraciones del electrocardiograma ${ }^{(46)}$. Cuadros similares se encuentra también en otras poblaciones expuestas ${ }^{(1,4,47-50)}$.

\section{Toxicidad crónica.-}

\section{En animales de experimentación}

No se encuentra disponible a la fecha información sobre toxicidad crónica de cianuros en animales ${ }^{(1-3)}$.

\section{Toxicidad humana}

El-Ghawabi informa aumento de tamaño de discreto a moderado en la tiroides y captación aumentada de yodo en trabajadores electroplateadores expuestos a cantidades de cianuro entre 6,4 y 10,4 ppm en un lapso de 5 a 15 años. Halla síntomas que incluyen dificultad respiratoria, cefalea, debilidad, trastornos del olfato y del gusto, desvanecimiento, faringitis, vómito, precordialgia, aumento significativo de hemoglobina y linfocitos (51). Otros autores citan a poblaciones expuestas en forma crónica a cianuro y describen dermatitis, urticaria, pápulas y en general erupción cutánea color escarlata, además de obstrucción nasal severa que lleva a epistaxis y perforación del septo ${ }^{(20,47)}$.

Carmelo, en 1955, examinó a 17 trabajadores que usaban compuestos cianúricos para fumigar; con tiempo de exposición entre 1 y 27 años, halló a 13 con síntomas tóxicos que iban desde pérdida de conciencia a problemas neurológicos, como vértigo, trastornos del equilibrio, nistagmus, precordialgia, anormalidades del electrocardiograma y gastritis ${ }^{(52)}$.

La exposición a cianuro en fumadores se asocia con ambliopía, atrofia óptica hereditaria de Leber's, neuritis retrolobular con atrofia del nervio óptico, desórdenes que involucran, además del cianuro, a déficit concomitante de vitamina $\mathrm{B} 12^{(6,11)}$.

OSHA documenta alteraciones similares en grupos ocupacionales ${ }^{(53)}$. 


\section{Toxicidad sobre el sistema reproductor y el desarrollo fetal.-}

\section{Toxicidad aguda}

No se encuentra disponible información de toxicidad aguda humana ni animal $^{(3)}$.

\section{Toxicidad subcrónica}

\section{En animales de experimentación}

Howar y Hanzal informan que ratas tratadas con cianuro de sodio hipodérmico a dosis de $0,61,1,31$ y $1,72 \mathrm{mg} / \mathrm{kg} / \mathrm{día}$, 3 días/semana por 3 meses, desarrollaron lesiones necróticas del cuerpo calloso y del nervio óptico. Otros estudios hallan mortalidad a todo nivel de dosis ${ }^{(16)}$.

\section{Toxicidad humana}

Collins y Martland, ya en 1908, encontraron invalidez permanente como resultado de exposición dérmica al cianuro en un trabajador de hotel que durante 2 años pulía plata con una solución de cianuro de potasio sin usar guantes; los síntomas incluyeron cefalea, dermatitis, diarrea, dolor y rigidez de espalda, debilidad de brazos y piernas, retención urinaria y pigmentación oscura en brazos, piernas y uñas, además de síntomas y signos semejantes a poliomielitis anterior aguda ${ }^{(54)}$.

\section{Toxicidad crónica}

\section{En animales de experimentación}

Doherty, en 1982 , administró cianuro por inyección hipodérmica continua a hámsteres gestantes a velocidad de 0,126, 0,1275 y $0,1295 \mathrm{mmol} / \mathrm{kg} / \mathrm{h}$, por 6 días; llegó a una dosis total equivalente a 30 y 40 veces la LD50. Halló alta incidencia de malformaciones en el desarrollo del tubo neural en toda la descendencia de los grupos estudiados. Las más comunes fueron exencefalia y encefalocele, pero además hidropericardio y torsión anormal de la cola en los productos ${ }^{\left({ }^{5}\right)}$. Otros estudios refieren que si a los animales se les administra simultáneamente tiocianato, este los protege contra los efectos tóxicos y teratógenos del cianuro ${ }^{(56)}$. Kiang describe asociación entre hipoxia celular inducida por cianuro y alteraciones genéticas ${ }^{(57)}$.

\section{Toxicidad humana}

Fumar durante el embarazo se asocia con mayor riesgo de peso bajo del producto al nacer y muerte perinatal. El producto de embarazadas fumadoras muestra aumento de la susceptibilidad del producto a los efectos del cianuro ${ }^{(11-12)}$.

Carelli, en 2002, asoció disfunción mitocondrial y neuropatía genética del nervio óptico inducidas por el cianuro ${ }^{(58)}$.

\section{Efectos de la exposición oral sobre órganos blanco primarios}

\section{Sistema nervioso central:}

La exposición subcrónica y crónica a cianuro en ratas produce cambios degenerativos en médula espinal y en células ganglionares del SNC, respectivamente (16).

En humanos, la ingestión cotidiana de yuca produce neuropatías, ambliopía y alteraciones del nervio óptico ${ }^{(32,33)}$.

\section{Tiroides:}

En ratas y en hámsteres expuestos se encuentra aumento del peso de tiroides y niveles disminuidos de tiroxina en plasma, lo que señala disminución de la función tiroidea ${ }^{(16,59)}$. En la tiroides de cerdas expuestas durante la gestación y lactancia se encuentra cambios histopatológicos ${ }^{(28)}$.

En humanos que consumen yuca en la dieta diaria se describe anormalidades en la glándula tiroides ${ }^{(31,60)} y$, en sus recién nacidos, hipotiroidismo congénito ${ }^{(61)}$.

Riñón:

Cerdas expuestas a cianuro durante la gestación y lactancia desarrollan hiperplasia glomerular ${ }^{(19,28)}$.

\section{Efectos teratógenos}

En hámsteres alimentados con yuca, la descendencia muestra disminución de peso al nacer y osificación incompleta. En grupos alimentados con dieta rica en amigdalina se observa exencefalia, encefalocele; además, anomalías en el desarrollo de arcos costales ${ }^{(29)}$.

En humanos, Carelli ${ }^{(58)}$ asocia cianuro y degeneración mitocondrial.

\section{Exposición respiratoria y efectos en órganos target primarios}

\section{Sistema nervioso central:}

En humanos, los efectos crónicos incluyen vértigo, perturbaciones del equilibrio y de las sensaciones olfativa y gustativa; nistagmus, nerviosismo, cefalea, debilidad y anorexia. En fumadores, se asocia la exposición al cianuro con neuritis del nervio óptico ${ }^{(1,2,11,32,33)}$.

Sistema cardiovascular y respiratorio:

Los humanos expuestos por su ocupación al cianuro desarrollan precordialgia, dificultad respiratoria, anormalidades del electrocardiograma. Sin embargo, estos efectos podrían ser secundarios a efecto sobre el SNC, más que a una acción directa del tóxico sobre esos sistemas ${ }^{(4,5,21)}$.

Tracto gastrointestinal:

En trabajadores expuestos a vapores de cianuro se describe náuseas, vómitos y gastritis, efectos que igual podrían ser atribuidos a acción primaria directa sobre el SNC ${ }^{(4,5,47)}$.

\section{Tiroides:}

En humanos la exposición por vía respiratoria a compuestos de cianuro condiciona aumento del tamaño de la tiroides ${ }^{(60)}$.

\section{Efectos teratógenos}

En animales expuestos por vía respiratoria a cianuro o a sus compuestos se describe alteraciones congénitas y aún alteraciones genéticas ${ }^{(55,58)}$.

En humanos, fumar durante el embarazo se asocia con neonatos de peso bajo y mayor riesgo de muerte perinatal. Sin embargo, para valorar este efecto se debería considerar a otros tóxicos que además del cianuro están presentes en el humo del tabaco y que pueden ser los responsables de esos efectos ${ }^{(11,12)}$.

\section{Efectos sobre órganos blanco secundarios}

Piel:

Los trabajadores expuestos a cianuro por cualquier vía pueden presentar pruri- 
to, pápulas, dermatitis e irritación crónica y severa de las fosas nasales ${ }^{(4,43,50,62)}$.

\section{TOXICIDAD DE LOS CIANUROS: EFECTOS CARCINOGÉNICOS}

No existe información disponible suficiente sobre efectos carcinogénicos del cianuro en seres humanos o en animales, por exposición oral, respiratoria, de contacto o por otras vías. Tampoco existen reportes en la literatura médica o toxicológica respecto a este efecto ${ }^{(7,14,63-69)}$.

\section{Clasificación del cianuro respecto a cáncer}

Se ubica al cianuro como 'tóxico clasificación D', es decir que, el cianuro es "no clasificable como carcinógeno humano" $(7,63-68)$

\section{Otros factores relacionados a sus efectos carcinógenos}

Para la valoración del efecto carcinogénico del cianuro tampoco existe información suficiente sobre factores directos ni cofactores relacionados a este poder ${ }^{(7,63-65)}$.

\section{ADDENDA}

\section{Protección al trabajador expuesto a cianuros}

Valores umbrales límites e índices de exposición

En salud ocupacional, y no obstante que en el trabajo con cianuro lo relevante es la exposición accidental a sus vapores que condiciona un suceso binario de necesidad casi siempre mortal, para el control del expuesto al cianuro por su ocupación se aplican valores o magnitudes considerados 'normales' o 'aceptados como normales'. Este control se debe hacer primero manteniendo al cianuro ambiental en el lugar de trabajo bajo el límite recomendado; segundo, proporcionando protección individual permanente y adecuada con equipos normalizados; y, tercero, por control médico del trabajador expuesto que incluya examen de salud ocupacional de periodicidad acorde a la
Tabla. Valores umbrales límites e índices de exposición de los trabajadores expuestos a cianuros.
Población de
trabajadores
Indicador de exposición

tiocianato- $\mathrm{U} 24 \mathrm{~h}$

OMS, NIOSH ${ }^{(63,68)}$
$50 \mathrm{mmol} / \mathrm{L}$

$70-85 \mathrm{mmol} / \mathrm{L}$

$250 \mathrm{mmol} / \mathrm{L}$
Cianógenos TLV-TWA $\mathrm{ACGIH}{ }^{(66)}$

\section{No fumadores}

No fumadores con alimentación rica en glúcidos cianogénicos

Fumadores
$10 \mathrm{ppm}$

$10 \mathrm{ppm}$

\section{0 ppm}

magnitud de la exposición, buscando estigmas del tóxico y midiendo indicadores de exposición ${ }^{(1,4,5,50)}$.

La Conferencia General Americana de Higienistas Industriales, $\mathrm{ACGIH}^{\circledR}$, propone directrices conocidas como valor umbral límite $\left(T L V^{\circledR}\right)$ e índice biológico de exposición $\left(\mathrm{BEI}^{\circledR}\right)$ para uso por higienistas industriales en la toma de decisiones con respecto a niveles de protección seguros en exposición a diversos peligros en el lugar de trabajo ${ }^{(66,67)}$. Para cianuros, la ACGIH adopta genéricamente un valor TLV TWA solo para 'cianógeno' y lo fija en $10 \mathrm{ppm}$. Para el acetonitrilo y similares, establece un valor TLV TWA de 20 ppm ${ }^{(6,667)}$.

NIOSH establece límites ambientales de 'exposición breve' para cianuro de hidrógeno $4,7 \mathrm{ppm}$ o $5 \mathrm{mg} / \mathrm{m}^{3}$, promediado durante un período de 15 minutos, el que no debe ser excedido en momento alguno durante el resto del día de labor. Para exposición breve de 10 minutos a sales de cianuro, fija el límite máximo también en $4,7 \mathrm{ppm}$ o $5 \mathrm{mg} / \mathrm{m}^{3}$. Otro parámetro $\mathrm{NIOSH}$ de protección para el trabajador que se expone por más de 1 hora/día, es el límite de riesgo inmediato para la salud y la vida -IDLH por sus siglas inglesas-, que para el cianuro de hidrógeno y sus sales es $50 \mathrm{ppm}$ o $25 \mathrm{mg} / \mathrm{m}^{3}{ }^{(68)}$.

Para monitorizar exposición a cianuros, en principio, se puede usar como indicadores de exposición a cianuro o tiocianato en sangre, plasma u orina; pero, el médico ocupacionista debe considerar que cada uno de ellos es objeto de cuestionamiento; del cianuro, su vida media corta, su concentración baja en el medio biológico -lo que crea problemas de medición- y su inestabilidad durante el almacenaje antes del procesamiento; del tiocianato, su presencia en varios alimentos de la dieta diaria -además de la yuca, repollo, col, leche, está en las bebidas alcohólicas, como la cerveza, y en el humo del tabaco-y su inconstancia en los medios biológicos al cesar la jornada de trabajo, pues varía si la muestra es tomada en viernes al final de jornada o a su inicio el lunes siguiente ${ }^{(1,4,63,68)}$.

De una u otra manera, para el control biológico al trabajador expuesto a cianuros es consenso que, además del control ambiental obligatorio ${ }^{(66)}$, se use un indicador de exposición y, de ellos, el BEI tiocianato en orina de 24 horas es el más indicado ${ }^{(63,68)}$.

Los valores del indicador y del TLV para trabajadores expuestos, se resumiría en la tabla.

\section{REFERENCIAS BIBLIOGRÁFICAS}

1. Ellemhorn MJ. Medical Toxicology. Penn, USA: William \& Wilkins; 1997.

2. Casarett and Doull's Toxicology. The Basic Science of Poisons. 7th Edition. McGraw-Hill. USA; 2004.

3. Agency for Toxic Substances and Disease Registry (ATSDR) [Internet]. Atlanta, GA: U.S. Department of Health and Human Services, Public Health Service; c2006 [citada el 15 de octubre 2009]. Disponible en: http://www.atsdr.cdc.gov/es/

4. Zenz C (ed). Occupational Medicine. 3rd Ed. St. Louis, USA: Ed Mosby-Year Book Inc; 1994.

5. La Dou J. Medicina Laboral y Ambiental, $2^{a}$ Ed. México: Ed. Manual Moderno; 1999.

6. Alarie Y. Toxicity of fire smoke. Crit Rev Toxicol. 2002;32(4):259-89.

7. International Agency for Research on Cancer. Overall evaluations of carcinogenicity to humans: As evaluated in IARC Monographs volumes 1-82 (at total of 900 agents, mixtures and exposures) [Internet]. Lyon, France: IARC; 2004 [citada el 7 de julio 2009]. Disponible en: http://www-cie.iarc. $\mathrm{fr} / \mathrm{monoeval} / \mathrm{crthall} . \mathrm{html}$ 
8. Gettler A0, Baine J0. The toxicology of cyanide. Am J Med Sci. 1938;195:182-98.

9. Landahl HD, Hermann RG. Retention of vapors and gases in the human nose and lung. Arch Ind Hyg Occup Med. 1950;1:36-45.

10.US Environmental Protection Agency. Health effects assessment for cyanides. Environmental Criteria and Assessment Office. Washington, DC: EPA; 1984.

11. Chen Y, Pederson LL, Lefoe NM. Exposure to environmental tobacco smoke (ETS) and serum thiocyanate level in infants. Arch Environ Health. 1990;45(3):163-7.

12. Hauth JC, Hauth J, Drawbaugh RB, Gilstrap LC 3rd, Pierson WP. Passive smoking and thiocyanate concentrations in pregnant women and newborns. Obstet Gynecol. 1984;63(4):519-22.

13. Harris R (ed). Patty's Industrial Hygiene. New York: John Wiley \& Son; 2000.

14. Ansell M, Lewis F. A review of cyanide concentrations found in human organs - A survey of literature concerning metabolism, "normal," nonfatal, and fatal body cyanide levels. J Forensic Med. 1970;17:148-55.

15. Okolie NP, Osagie AU. Differential effects of chronic cyanide intoxication on heart, lung and pancreatic tissues. Food Chem Toxicol. 2000;38:543-8.

16. Howard JW, Hanzal RF. Sub-chronic and chronic toxicity to rats of food treated with hydrogen cyanide. J Agric Food Chem. 1955;3:325-9.

17. Westley J. Rhodanese and the sulfane pool. En: Jacoby WB, ed. Enzymatic Basis of Detoxication, Vol. II. New York: Academic Press; 1980. p. 24562.

18. Aminlari M, Li A, Kunanithy V, Scaman CH. Rhodanese distribution in porcine (Sus scrofa) tissues. Comp Biochem Physiol B Biochem Mol Biol. 2002;132(2):309-13.

19. Leuschner J, Winkler A, Leuschner F. Toxicokinetic aspects of chronic cyanide exposure in the rat. Toxicology Lett. 1991;57:195-201.

20. National Institute for Occupational Safety and Health (NIOSH). Occupational Exposure to Hydrogen. Cyanide and Cyanide Salts. U.S. Department of Education and Welfare, Public Health Service. Rockville: NIOSH; 1976.

21. Tsuge K, Kataoka M, Seto Y. Cyanide and thiocyanate levels in blood and saliva of health adult volunteers. J Health Sci. 2000;46(5):34350.

22. Baskin SI, Wilkerson G, Alexander K, Blitstein AG. Cardiac effects of cyanide. En: Ballantyne B, Marrs TC (Eds). Clinical and experimental toxicology of cyanides. Bristol, UK: Wright Publishers; 1987. p. 62-79.

23. Hardy HL, Boylen GW Jr. Cyanogen, hydrocyanic acid and cyanides. En: Parmeggiani L. Ed. Encyclopaedia of Occupational Health and Safety, 3rd Ed. Vol. 1. Geneva: International Labour Office; 1983. p. 574-7.

24. Soto-Blanco B, Marioka PC, Górniak SL. Effects of long term low-dose cyanide administration to rats. Ecotoxicol Environ Saf. 2002;53(1):37-41.
25. Wolnik KA, Fricke FL, Bonnin E, Gaston CM, Satzger RD. The Tylenol tampering incidenttracing the source. Anal Chem. 1984;56:466A474A.

26. Losek JD, Rock AL, Boldt RR. Cyanide poisoning from a cosmetic nail remover. Pediatrics. 1991;88:33740.

27. Tewe 00, Maner JH. Long-term and carry-over effect of dietary inorganic cyanide (KCN) in the life cycle performance and metabolism of rats. Toxicol Appl Pharmacol. 1981;58:1-7.

28. Tewe 00, Maner JH. Performance and pathophysiological changes in pregnant pigs fed cassava diets containing different levels of cyanide. Res Vet Sci. 1981;30:147-51.

29. Frakes RA, Sharma RP, Willhite CC, Gomez G. Effect of cyanogenic glycosides and protein content in cassava diets on hamster prenatal development. Fundam Appl Toxicol. 1986;7:191-8.

30. Willhite CC. Congenital malformations induced by laetrile. Science. 1986;215:1513.

31. Ermans AM. General conclusions. En: Ermans AM, Mbulamoko NM, Delange F, Ahlvertartia R (Ed). Role of cassava in the etiology of endemic goiter and cretinism. Report on International Development Research Centre. Ottawa, Canada; 1980. p. 147-52.

32. Howlett WP, Brubaker GR, Mlingi N, Rosling $\mathrm{H}$. Konzo, an epidemic upper motor neuron disease studied in Tanzania. Brain. 1990;113:22335.

33. Ministry of Health, Mozambique. An epidemic of spastic Para-paresis, associated with chronic cyanide intoxication in a cassava staple area of Mozambique. 1. Epidemiology and clinical and laboratory findings in patients. Bull WHO. 1984;62:477-84.

34. Mlingi N, Poulter NH, Rosling H. An outbreak of acute intoxications from consumption of insufficiently processed cassava in Tanzania. Nutr Res. 1992;12 (6):677-87.

35. Okafor PN, Okorowkwo CO, Maduagwu EN. Occupational and dietary exposures of humans to cyanide poisoning from large-scale cassava processing and ingestion of cassava foods. Food Chem Toxicol. 2002;40(7):1001-5.

36. Oluwole OSA, Onabolu AO, Sowunmi A. Exposure to cyanide following a meal of cassava food. Toxicol Lett. 2002;135:19-23

37. Palmer IS, Olson OE. Partial prevention by cyanide of selenium poisoning in rats. Biochem Biophys Res Commun. 1979;90:1379-86.

38. Hertting GO, Kraupp E, Schnetz K, Wuketich S. Untersuchungen über die Folgen einer chronischen Verabreichung akut toxischer Dosen von Natrium Cyanid an Hunden. Acta Pharmacol Toxicol. 1960;17:27-43.

39. Philbrick DJ, Hopkins JB, Hill DC, Alexander JC, Thomson RG. Effects of prolonged cyanide and thiocyanate feeding in rats. J Toxicol Environ Health. 1979;5:579-92.

40. Higgins EA, Fiorca V, Thomas AA, Davis HV. Acute toxicity of brief exposures to $\mathrm{HF}, \mathrm{HCl}, \mathrm{NO2}$, and
HCN with and without CO. Fire Technol. 1972; 8:120-30.

41. Rieders F. Noxious gases and vapors. I. Carbon monoxide, cyanides, methemoglobin, and sulfhemoglobin. En: DiPalma JR (Ed). Drills Pharmacology in Medicine. New York: McGraw Hill Book Co;. 1971. p. 1198-205.

42. Purser DA, Grimshaw P, Berrill KR. Intoxication by cyanide in fires: A study in monkeys using polyacrylonitrile. Arch Environ Health. 1984;39:394-400.

43. Ballantyne B. Acute percutaneous systemic toxicity of cyanides. J Toxicol Cut Ocular. 1994;13(3):24962.

44. Ballantyne B. Acute systemic toxicity of cyanides by topical application to the eye. J Toxicol Cut Ocular. 1983;2:119-29.

45. Hugod C. Myocardial morphology in rabbits exposed to various constituents of tobacco smoke - an ultrastructural study. Atherosclerosis. 1981;4:181-90.

46. Sandberg CG. A case of chronic poisoning with potassium cyanide. Act Med Scand. 1967;181:233-6.

47. Wuthrich F. Chronic cyanide poisoning as industrial intoxicant. Schweiz Med Wochenschr. 1954;84:105-7.

48. National Institute for Occupational Safety and Health (NIOSH) [Internet]. http://www.cdc.gov/ niosh/npg/npg.html. Visita mayo 2009.

49. NYSDOH. The facts about cyanides. Technical information [Internet]. New York, State Department of Health; 2004 [Citado el 22 de setiembre 2009]. Disponible en: http://www.health.state.ny.us/ nysdoh/bt/chemical_terrorism/docs/cyanide_ tech.pdf

50. Levy VS, Wegman DH (Eds). Occupational Health. Recognizing and Preventing Work-Related Disease. Boston: Little, Brown and Co; 1988.

51.El-Ghawabi SH, Goofar MA, El-Saharti AA, et al. Chronic cyanide exposure: a clinical, radioisotope and laboratory study. $\mathrm{Br} \mathrm{J}$ Ind Med. 1984;38:355.

52. Carmelo S. New contributions to the study of subacute and chronic hydrocyanic acid intoxication in men. Rass Med Ind. 1955;24:254-71.

53. OSHA. Appendix A. Safety and health regulations: Gases, vapours, fumes, dusts, and mists [Internet]. Washington, DC: Occupational Safety and Health Administration; 2004 [citado el 18 de octubre 2009]. Disponible en: http://www.osha. gov/pls/oshaweb/owadisp.show_document?p_ table $=$ STANDARDS\&pid $=10629$

54. Collins J, Martland HS. Disease of the primary motor neurons causing the clinical picture of acute poliomyelitis: The result of poisoning by $\mathrm{KCN}-\mathrm{a}$ clinical contribution to the toxic effects of KCN upon the peripheral motor neurons. J Nerv Dis. 1908;35:417-26.

55. Doherty PA, Ferm VH, Smith RP. Congenital malformations induced by infusion of sodium cyanide in the golden hamster. Toxicol Appl Pharmacol. 1982;64:456-64. 
56. Curry SC, Carlton MW, Raschke RA. Prevention of foetal and maternal cyanide toxicity from nitroprusside with co-infusion of sodium thiosulfate in gravid ewes. Anesth Analg. 1997;84:1121-6.

57. Kiang JG, Warke VG, Tsokos GC. NaCNinduced chemical hypoxia is associated with altered Gene expression. Mol Cell Biochem. 2003;254:211-6.

58. Carelli V, Ross-Cisneros FN, Sadun AA. Optic nerve degeneration and mitochondrial dysfunction: Genetic and acquired optic neuropathies. Neurochem Int. 2002;40:573-84.

59. Frakes RA, Sharma RP, Willhite CC. Developmental toxicity of a cianogenic glycoside linamarin in the golden hamster. Teratology. 1985;31:241-6.

60. Banerjee KK, Bishayee A, Marimuthu P. Evaluation of cyanide exposure and its effect on thyroid function of workers in a cable industry. J Occup Environ Med. 1997;39(3):258-60.

61.Dorea JG. Maternal thiocyanate and thyroid status during breast feeding. I Am Coll Nutr. 2004;23(2):97-101.
62. Walton DC, Witherspoon MG. Skin absorption of certain gases. J Pharmacol Exptl The. 1926;26:315-24.

63. World Heath Organization (WHO). Hydrogen cyanide and cyanides: Human health aspects. Geneva, Switzerland: World Heath Organization; 2004. p. 1-67.

64. International Agency for Research on Cancer (IARC). Monographs on the valuation of carcinogenic risk of chemicals to humans. Suppl 7. Lyon. World Heath Organization; 1987.

65.US National Toxicology Program. Department of Health and Human Services. Report on Carcinogens. 11th Report on Carcinogens; 2005. http://ntp.niehs.nih.gov/index. cfm?objectid $=72016262$-BDB7-CEBAFA60E922B18C2540

66. ACGIH Threshold Limit Values for Chemical substances and Physical Agents \& Biological Exposure Indices. Cincinnati, OH: TLV \& BEl; 2008.

67.ACGIH. Threshold Limit Values for Chemical substances and Physical Agents \& Biological
Exposure Indices. TLV \& BEI. 2 008. www.acgih. org/TLV/.

68. National Institute for Occupational Safety and Health. A recommended standard for occupational exposure: hydrogen cyanide and cyanide salts. US Depart E W PHS. CDC NIOSH; 2005.

69. WHO. International Programme on Chemical Safety. Section II. Geneva: World Health Organization; 2004.

Manuscrito recibido el 18 de diciembre de 2009 y aceptado para publicación el 23 de febrero de 2010.

\section{Correspondencia:}

Augusto V. Ramírez, MD. OH.

Salud Ocupacional. Clínica Los Fresnos

Los Nogales 179

Cajamarca, Perú

Correo-e: augustovram@yahoo.es 